\title{
Adenotonsillar hypertrophy as a cause of failure to thrive
}

\author{
ANN G SHEEHAN, MB, MRCPI, R BRENT SCOTT, MDCM, FRCPC, HELEN M MACHIDA, MD, FRCPC
}

\begin{abstract}
Two infants aged 11 and 15 months presented to the Gastroenterology Clinic at Alberta Children's Hospital because of failure to thrive. Clinical and taboratory investigations excluded any underlying abnormality of the gastrointestinal tract. Because of a history of obstructive upper respiratory symptoms, both were referred for ear, nose and throat evaluation, and both were found to have partial upper airway obstruction secondary to adenotonsillar hypertrophy. Subsequent adenotonsillectomy led to resolution of obstructive upper respiratory symptoms and dramatic increases in weight gain and growth. Adenotonsillar hypertrophy should be included among the potential causes of failure to thrive in infancy, especially if the child has a history of obstructive upper respiratory symptoms. Can J Gastroenterol 1990;4(8):485-488
\end{abstract}

Key Words: Adenotonsillar hypertrophy, Failure to thrive

\section{Hypertrophie adéno-amygdalienne et retard de croissance}

RESUME: Deux jeunes enfants âgés de 11 et 15 mois ont été conduits à la clinique de gastro-entérologie de l'Alberta Children's Hospital pour retard de croissance. Les examens cliniques et de laboratoire n'ont révélé aucune anomalie sous-jacente des voies gastro-intestinales. Ayant auparavant présenté des troubles obstructifs des voies aériennes supérieures, tous deux ont été envoyés en ORL pour subir une évaluation. Elle a révélé une obstruction partielle des voies aériennes supérieures secondaire à une hypertrophie adéno-amygdalienne. Une adéno-amygdalectomie a conduit à la résolution des symptômes et résulté en une augmentation spectaculaire du poids et de la taille des patients. L'hypertrophie adéno-amygdalienne devrait figurer parmi les causes possibles de retard de croissance chez les nourrissons, surtout chez l'enfant qui présente des troubles obstructifs des voies aériennes supérieures.

Alberta Children's Hospital, University of Calgary, Calgary, Alberta

Correspondence and reprints: Dr Helen Machida, Alberta Children's Hospital, 1820

Richmond Road SW, Calgary, Alberta T2T 5C7. Telephone (403) 229-7211

Received for publication April 25, 1990. Accepted July 24, 1990
T ONSILLECTOMY AND ADENOIDECtomy remain the most common major operations carried out in childhood (1). Surgical indications vary from recurrent or chronic tonsillitis and otitis media to the more extreme alveolar hypoventilation with cor pulmonale (1). Recently, it was recognized that adenotonsillar hypertrophy may also present as failure to thrive which resolves with tonsillectomy and adenoidectomy (2-9). Two similar cases are reported in which children aged 11 and 15 months, respectively presented with failure to thrive due to partial upper airway obstruction from tonsillar and adenoidal hypertrophy. In both children, tonsillectomy and adenoidectomy resulted in dramatic weight gain and catch-up growth. These cases are reported to increase awareness of this recently recognized clinical entity, and to emphasize the importance of an ear, nose and throat evaluation in an infant who presents with both failure to thrive and obstructive upper respiratory symptoms.

\section{CASE ONE}

An 11-month-old female was referred to the outpatient Gastroenterology Clinic at Alberta Children's 

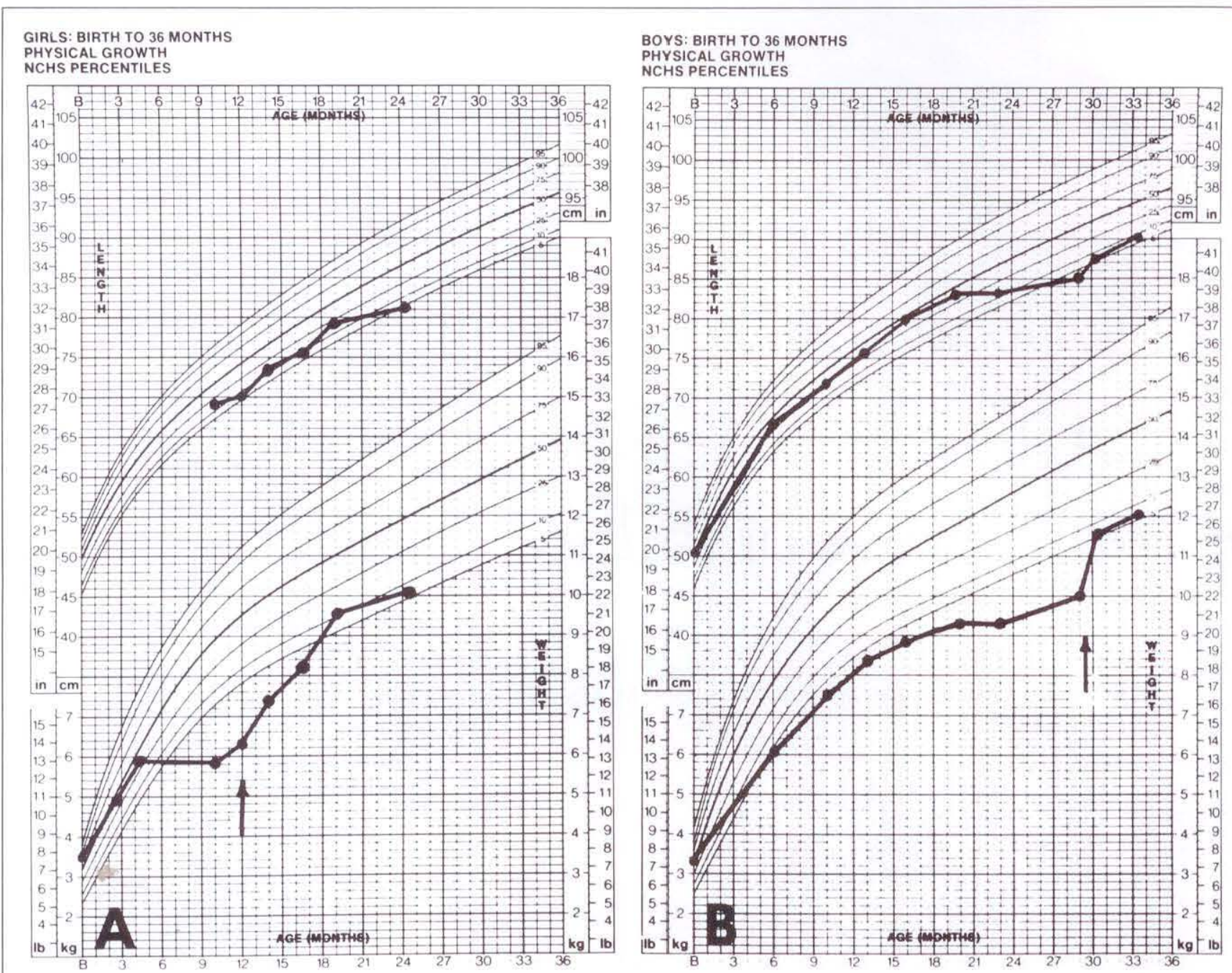

Figure 1) Weight and height before and after adenotonsillectomy in case 1 (left) and case 2 (right) illustrating the weight gain which followed adenotonsillectomy

Hospital, University of Calgary, because of failure to thrive.

She had been the product of a normal pregnancy with a birth weight of $3410 \mathrm{~g}$ (75th percentile). She was breastfed from birth. Pablum and cereals were introduced at five months, with progression to puréed table food shortly thereafter. Whole milk was started at nine months. The patient's history was unremarkable apart from very frequent upper respiratory tract infections: eight in the previous six months. There was also a history of laboured mouth breathing and marked snoring during sleep. Detailed dietary history revealed a caloric intake equal to $66 \%$ of recommended dietary allowances. The fall-off in the patient's height and weight is illustrated in Figure 1.
The patient's parents, her 10-yearold brother and four-year-old sister were well. The younger sibling had had a fundoplication for gastroesophageal reflux. A paternal cousin had three children with cystic fibrosis.

Physical examination revealed a thin wasted infant whose weight of 5.82 $\mathrm{kg}$ was below the fifth percentile, and whose height of $69 \mathrm{~cm}$ was greater than the 25 th percentile. She had nasal congestion and rhinorrhea, and was mouth breathing. Her tonsils were enlarged but not inflamed and met in the midline. Examination was otherwise unremarkable.

Laboratory investigations including complete blood count, prothrombin time, partial thromboplastin time, calcium, phosphorus, alkaline phospha- tase, total protein, albumin, electrolytes, urea, creatinine, liver function tests, serum immunoglobulins, cholesterol, urine metabolic screen including amino acids and organic acids, thy. roxine and thyroid stimulating hormone levels were all normal. Urinalysis and culture were negative. A three-day quantitative fecal fat collection was normal with an excretion of $3 \%$ of intake. The sweat chloride was normal at $7 \mathrm{mmol} / \mathrm{L}$.

Two subsequent outpatient visits revealed persistent anorexia with failure to gain weight. Because of chronic post nasal airway obstruction, loud snoring at night and mouth breathing, an ear, nose and throat consult was requested. Examination revealed no serviceable nasal airway 
due to enlarged adenoids and oral examination again demonstrated grossly enlarged but noninflamed tonsils touching at the midline. As it was thought that severe adenotonsillar hy. pertrophy was contributing significantly to the infant's anorexia and poor weight gain, tonsillectomy and adenoidectomy were performed at the age of one year.

One week prior to surgery, the infant was admitted for supplemental nighttime nasogastric feedings to improve nutritional status. These feeds were discontinued postoperatively as oral intake improved. Two months after adenotonsillectomy she had gained 1.2 kg. At 19 months, her weight was $9.5 \mathrm{~kg}$ (10th percentile), and her height was $710 \mathrm{~cm}$ (25th percentile). Her weight as a percentage of ideal weight for height before surgery was $72.5 \%$ and after surgery at 19 months it was $96 \%$.

\section{CASE TWO}

A 15-month-old male was referred to the outpatient Gastroenterology Clinic because of failure to thrive.

History revealed a normal delivery at term with a birth weight of $3380 \mathrm{~g}$. He was breastfed for seven weeks and then switched to Similac (Ross Laboratories). At three and four months of age, he had acute gastroenteritis and dehydration requiring hospitalization. After the second admission, he was switched to Nutramigen (Mead Johnson). In addition, for the first seven months of his life, the patient had upper respiratory infections with a chronic cough, nasal congestion and rhinorthea. During this time he was given at least 10 courses of antibiotics.

At eight months he was started on whole cow's milk. From eight to 29 months, interval examinations revealed a thin wasted child whose weight was consistently below the fifth percentile and whose height was between the 25 th and 50 th percentiles (Figure 1). He was a mouth breather with nasal speech and his tonsils were enlarged but not inflamed. At 20 months, asthma was diagnosed and he was started on theophylline (Somophyllin; Fisons) and salbutamol (Ventolin; Glaxo).
Both parents were well, but his mother had been on a gluten-free diet since infancy because of a clinical diagnosis (not biopsy proven) of celiac disease. A two-and-a-half-year-old sibling was healthy.

Subsequent laboratory investigations including a complete blood count, prothrombin time, partial thromboplastin time, calcium, phosphorus, alkaline phosphatase, total protein, albumin, electrolytes, urea, creatinine, urine metabolic screen including amino and organic acids, liver function tests and cholesterol were normal. A three-day quantitative fecal fat collection showed an excretion of $0.8 \%$ of intake, and a caloric intake that met the recommended daily allowance for age. A jejunal biopsy showed normal villous architecture. Sweat chloride was 9 $\mathrm{mmol} / \mathrm{L}$.

At 29 months the child continued to have intermittent upper respiratory infections. A blocked nasal airway and chronic mouth breathing made eating difficult. At night he snored loudly and awakened intermittently with respiratory difficulty due to partial upper airway obstruction which was not asthma. His weight of $10 \mathrm{~kg}$ remained at less than the fifth percentile. On examination, he had a completely obstructed upper airway and was drooling because of constant mouth breathing. Post nasal space $\mathrm{x}$-ray showed adenoidal hypertrophy and posterior tonsillar enlargement. Maxillary sinuses were opaque. A tonsillectomy and adenoidectomy were performed.

One month later the child was eating well, breathing through his nose and sleeping throughout the night. He had gained $1.6 \mathrm{~kg}$. Three months later and still well, his weight had increased to $12.2 \mathrm{~kg}$ (between the fifth and 10th percentiles) and his height of $90 \mathrm{~cm}$ was on the fifth to 10 th percentile. His weight as a percentage of ideal weight for height before surgery was $89 \%$ and two months postoperatively it was $100 \%$.

Seven months postoperatively, he was again symptomatic with anorexia, increased mouth breathing and snoring. His weight of $15.5 \mathrm{~kg}$ remained in the 10 th to 25 th percentile. Sinus $x$-rays and high kilovoltage views of the neck showed enlargement of the residual adenoidal tissue and bilateral opacification of the maxillary sinuses. Ear, nose and throat examination revealed prominent inferior turbinates obstructing the nasal airway. A repeat adenoidectomy was performed with submucosal diathermy of inferior turbinates. The patient did well postoperatively and had normal subsequent growth velocity.

\section{DISCUSSION}

Among the more commonly encountered problems seen in a pediatric gastroenterology clinic is that of the infant or child who is failing to thrive. The differential diagnosis includes virtually every chronic disease of childhood. Fortunately, a probable diagnosis can generally be reached by a thorough history and physical examination (10).

There was a delay in diagnosis in both of these cases (only one month in the first case, but almost 14 months in the second). The delay is partly attributable to the fact that five to eight upper respiratory tract infections per year are within normal limits for this age group and can result in temporary adenotonsillar hypertrophy. In retrospect, in case 2 , the significant contribution of persistent respiratory symptoms to the failure to thrive was not appreciated. As a result, extensive investigations were carried out which did not identify the underlying problem. It is only in recent years that adenotonsillar hypertrophy causing obstructive sleep apnea has been recognized as a cause of growth failure, which can be treated with removal of tonsils and adenoids (2-9). Previous reports have also highlighted this delay in diagnosis (9). Brouillette et al (9) felt that there were two possible contributing factors: first, a lack of awareness of the entity, and second, the fact that most children look surprisingly normal when awake, despite snoring retractions and intermittent complete obstruction when asleep. Delay in diagnosis may have serious consequences, as chronic problems can result in failure to thrive, developmental delay and cor pulmonale (9-12).

Obstructive sleep apnea was de- 
scribed in adults in 1966. However, the entity was first reported in children by Guilleminault in 1976 (11). The most common cause of this type of partial upper airway obstruction in children was adenotonsillar hypertrophy. A variety of symptoms and signs are described. During the day, there is often excessive sleepiness, mouth breathing, behavioural changes and respiratory congestion. A more recent report suggests that vomiting may be a feature of obstructive sleep apnea (3). However, most frequently, symptoms occur at night and include excessive snoring, restless sleep, arousal during sleep, and apnea observed by the parents. Confirmation of the diagnosis can be done by observing patients during sleep, and by polygraphic recordings that demonstrate hypoxemia $\left(\mathrm{P}_{\mathrm{a}} \mathrm{O}_{2}\right.$ less than $\left.50 \mathrm{mmHg}\right)$, hypercarbia $\left(\mathrm{P}_{\mathrm{a}} \mathrm{CO}_{2}\right.$ more than 45 $\mathrm{mmHg}$ ) and changes in heart and respiratory rate consistent with obstructive apnea. In Brouillette's review (9), the mean age of onset of symptoms was 21 months, but there are reports of infants requiring adenotonsillectomy as early as nine months of age.

While poor growth is well documented in patients with obstructive sleep apnea (2-9), there is controversy

ACKNOWLEDGEMENTS: The authors thank Elinor Rae for typing the manuscript.

\section{REFERENCES}

1. Paradise JL. Tonsillectomy and adenoidectomy. Pediatr Clin North Am 1981;28:881-91.

2. Schiffmann R, Faber J, Eidelman AI. Obstructive hypertrophic adenoids and tonsils as a cause of infantile failure to thrive: Reversed by tonsillectomy and adenoidectomy. Int J Pediatr Otorhinolaryngol 1985;9:383-7.

3. Gleghorn E. Tonsillar hypertrophy presenting as vomiting and failure to thrive in toddlers. Published in the proceedings of the North American Society for Pediatric Gastroenterology and Nutrition, July 1989. (Abst)

4. Lind JG, Lundell BPW. Tonsillar hyperplasia in children. A cause of obstructive sleep apnea, $\mathrm{CO}_{2}$ retention as to whether recurrent tonsillitis in the absence of obstructive symptoms has an adverse effect on growth (13-15). Grace et al (13) and Mills and Hibbert (14) found no significant weight gain in a group of children post tonsillectomy compared to controls. However, Barr and Osborne (15) found a 20\% increase in weight in a group of children post tonsillectomy. It would appear that the presence of obstructive symptoms is the principal factor affecting growth (13).

A review of the literature (2-9) suggests that with relief of obstruction, rapid catch-up growth occurs within three to 12 months of surgery. The present data are consistent with these reports: case 1 took nine months to achieve the 10th percentile for weight; case 2 regained his previous weight percentile within two months. Case 2 did not regain his initial height percentile within this period of time, possibly because symptoms recurred and a second operation was needed for relief of obstruction, and partly because of asthma.

The mechanism of failure to thrive in children with obstructive sleep apnea remains speculative. Consistent with previous reports, the first of the present patients had an inadequate caloric intake for age, and demonstrated

and retarded growth. Arch Otolaryngo 1982;108:650-4.

5. Hodges S, Wailoo MP. Tonsillar enlargement and failure to thrive. $\mathrm{Br}$ Med J 1987:295:541-2.

6. Kravath RE, Pollak CP, Borlwiecki B. Hypoventilation during sleep in children who have lymphoid airway obstruction treated by nasopharyngeal tube and $T$ and $A$. Paediatrics $1977 ; 6: 865-71$

7. Everett AD, Koch WC, Saulsbury FT. Failure to thrive due to obstructive sleep apnea. Clin Pediatr 1986;26:90-2

8. Bate TWP, Price DA, Holme CA, McGucken RB. Short stature caused by obstructive apnea during sleep. Arch Dis Child 1984:59:78-80.

9. Brouillette RT, Fernbach SE, Hunt CE. Obstructive sleep apnea in infants and children. I Pediatr 1982;100:31-40.

10. Sills RH. Failure to thrive. The role of clinical and laboratory evaluations. Am J Dis Child 1978;132:967-9. an increase in appetite and weight gain after surgery.

Another theory is that tissue acidosis occurring during periods of apnea may impair end organ response to growth factors (8). The reduction of REM sleep in association with obstructive sleep apnea may also impair growth hormone release and further contribute to poor growth. The reversibility of decreased growth hormone secretion in a patient with obstruc. tive sleep apnea following tracheostomy has been demonstrated (16).

These two case reports emphasize the importance of considering upper airway obstruction secondary to adenotonsillar hypertrophy as a potential cause of failure to thrive in infants. An increased clinical awareness of this entity should lead to earlier recognition and surgical intervention in affected children. When one suspects adenotonsillar hypertrophy as a cause of failure to thrive, one must specifically ask about symptoms at night, eg, snoring, laboured breathing, agitated arousal and sleep apnea. Excessive daytime sleepiness is also a significant clue to the syndrome, reflecting a disturbed sleep pattern. Polygraphic monitoring during sleep can be used to confirm the diag. nosis if there is any doubt.

11. Guilleminault C, Eldridge FL, Simmons FB, et al. Sleep apnea in eight children. Pediatrics 1976;58:23-30.

12. Yates DW. Adenotonsillar hypertrophy and cor pulmonale. $\mathrm{Br}$ ] Anaesth 1988;61:355-9.

13. Grace A, Veitch D, Ryan R, Barnes N, Coles T. Recurrent tonsillitis and growth in children. Int J Pediatr Otorhinolaryngol 1988;16:91-3.

14. Mills RP, Hibbert J. The effects of recurrent tonsillitis on growth and cervical lymphadenopathy in children. Int ] Pediatr Otorhinolaryngol 1983;6:77-82.

15. Barr GS, Osborne J. Weight gain in children following tonsillectomy. J Laryngol Otol 1988;102:595-7.

16. Goldstein SJ, Wu RHK, Thorpy MJ, Shprintzon RS, Marion RE, Saenger P. Reversibility of deficient sleep entrained growth hormone secretion in a boy with achondroplasia and obstructive sleep apnea. Acta Endocrinol 1987;116:95-101. 


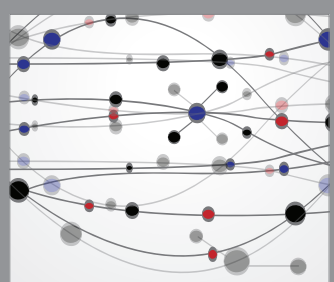

The Scientific World Journal
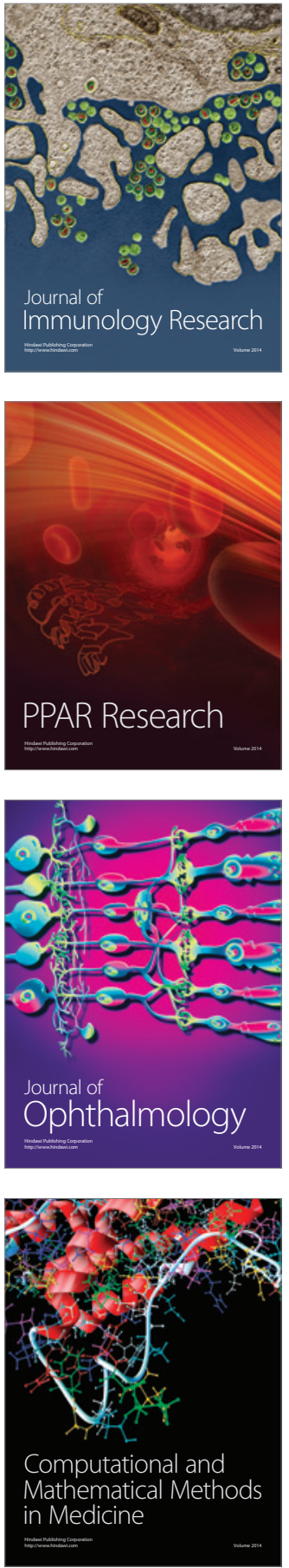

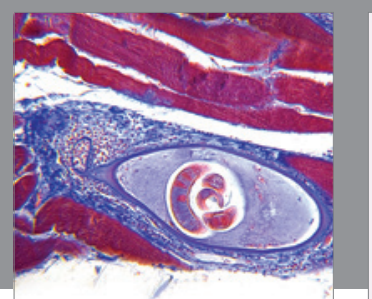

Gastroenterology Research and Practice

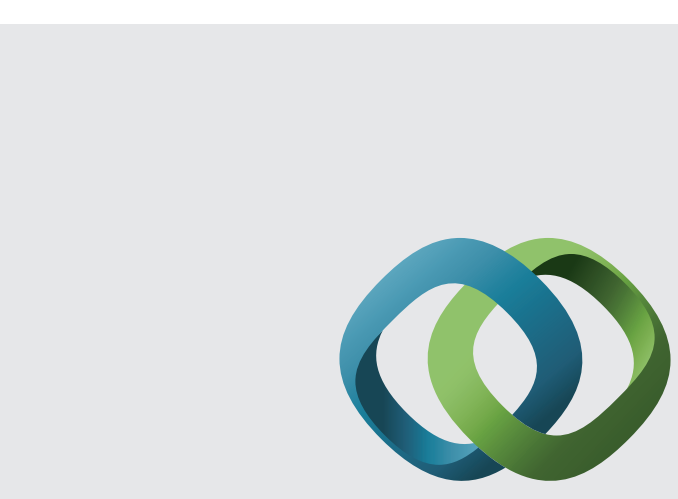

\section{Hindawi}

Submit your manuscripts at

http://www.hindawi.com
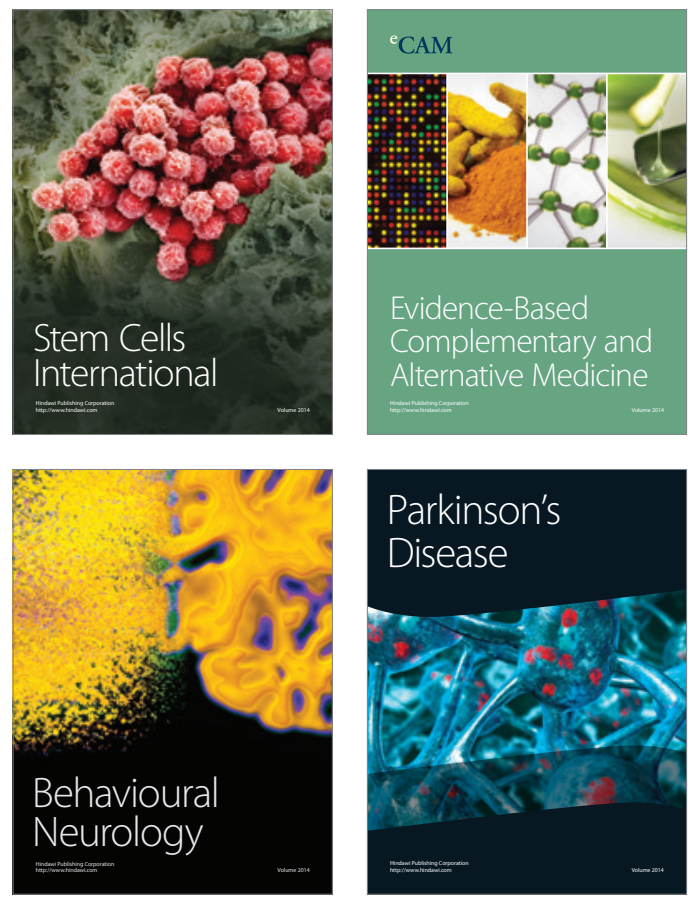
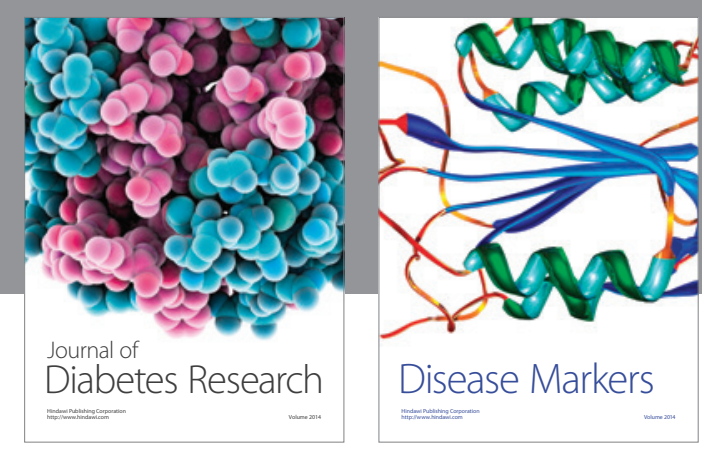

Disease Markers
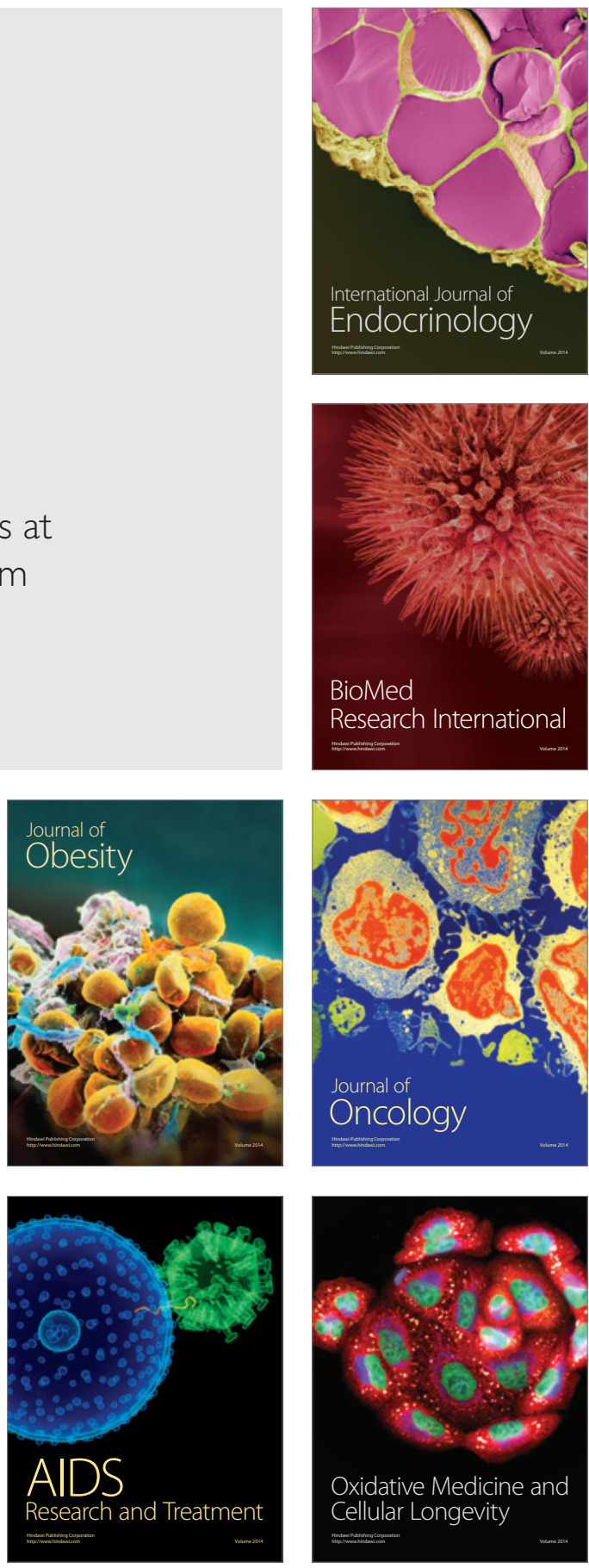